\title{
Drug Prescribing Trends in a General Hospital in Sharjah, United Arab Emirates
}

\author{
Suleiman I. Sharif ${ }^{1}$, Alya H. Alabdouli ${ }^{1}$, Rubian S. Sharif ${ }^{2, *}$ \\ ${ }^{1}$ Department of Pharmacy Practice \& Pharmacotherapeutics, College of Pharmacy, University of Sharjah, United Arab Emirates \\ ${ }^{2}$ Faculty of Dentistry, Ajman University of Science \& Technology, Ajman, United Arab Emirates \\ *Corresponding author: sharifsi@sharjah.ac.ae
}

Received December 28, 2012; Revised February 02, 2013; Accepted February 16, 2013

\begin{abstract}
Prescription analysis illustrates the prescribing behavior of physicians and pinpoint areas of improvement, if any, to help in rationalizing drug use. The present study was undertaken to investigate the trends of drug prescribing by consultants in a general hospital in Sharjah, United Arab Emirates. 1239 prescriptions were collected from a governmental general hospital covering the month of April, 2011. The prescriptions were issued to outpatients. Prescribing patterns were analyzed using WHO indicators and focusing mainly on information related to patient, prescriber and the prescribed drugs. The average number of drugs per prescription was 2.2. All prescriptions were head lettered in name of hospital and were handwritten. Generic drugs were prescribed in $19.4 \%$ of all prescriptions. Name of patient, age, and sex were present in $100 \%$ and so the name, signature and official stamp of the prescriber. None of the prescription contained address of patient, diagnosis of complaint or a history of allergy. The dose of the prescribed drug with its frequency of administration and route of administration were present in $73.2 \%$ and $5.6 \%$ of prescriptions respectively whereas duration of treatment was mentioned in all prescriptions. Patients were prescribed one, two, three, four or more than four drugs per prescription in $21.3 \%, 22.18 \%, 18.56 \%$, $11.94 \%$ and $25.66 \%$ respectively. The most commonly prescribed therapeutic classes of drugs were antihypertensive drugs $(35.68 \%)$, antiepileptics (30.9\%), antidiabetics (19.49\%), nonsteroidal anti-inflammatory drugs (NSAIDs $8.19 \%)$ and anticoagulants (5.57\%). Diuretics (28.39\%), beta blockers $(25.93 \%)$ and angiotensin receptor blockers $(24.28 \%)$ were the most commonly prescribed drugs of the first class $(28.39 \%)$. The most frequently prescribed antiepileptic was sodium valproate $(60.38 \%)$ and antidiabetic was metformin $(58.71 \%)$. The present study pinpointed areas for further improvements to prescription writing and suggests that feedback through personal interviews and workshops may be an effective intervention to enforce rational drug use.
\end{abstract}

Keywords: Trends, Prescribing, General hospital, Analysis

\section{Introduction}

Irrational drug prescribing is still a global problem with its impact being more deterrent on developing countries [1]. Consequences of improper drug use include among others exhaustion of the limited health budget, increased incidence of serious adverse effects, drug interactions, non-compliance and emergence of resistant microbial strains [1]. The World Health Organization (WHO) compiled a set of core drug use indicators that are useful for studying patterns of drug prescribing in health-care facilities $[2,3]$. In UAE, health regulations are very strict with regard to drug prescribing and also prescription dispensing [4]. Ideally a prescription should carry all necessary information pertinent to patient such as name, age, sex, address, and a brief diagnosis of the condition for which the drug(s) is indicated. Particulars of the prescriber are also important which include name, address, signature, and means of contact, specialty, and medical registration number. The present study analyzed the prescriptions issued in a governmental general hospital, covering all medical specialties, in Sharjah, United Arab Emirates. The objective was to investigate the prescribing patterns of consultant physicians. Analysis of prescriptions can also pinpoint deficiencies and the results of such studies can be utilized as an effective intervention by feeding it back to and discussing it with the prescribers and health authorities to promote rational drug prescribing.

\section{Materials and Methods}

Prescriptions issued to outpatients in a governmental general hospital in Sharjah, United Arab Emirates were collected from the pharmacy of the hospital covering the month of April, 2011. The total number of prescriptions was 1239. The prescriptions were subjected to analysis using the WHO drug use indicators [2]. In each prescription we analyzed the presence and deficiencies in information of patient, prescriber and the prescribed drug(s). Patient's information studied includes name, age, sex, and address, diagnosis of complaint, and history of allergy. Information with regard to the prescribing consultant covered name, signature, license number, and address.

Concerning the prescribed drug(s), we determined the presence or deficiency of the dose, and frequency and route of administration. We also studied the readability of 
the prescription, the number of drugs per prescription and the extent of prescribing generic drugs. Prescriptions were also analyzed for the most commonly prescribed therapeutic classes and the most frequently prescribed drug of each class.

Results are expressed as the percentage of present indicators of total number of prescriptions.

\section{Results}

The average number of drugs per prescription was 2.2. All prescriptions were head lettered in the name of hospital and were handwritten. Readability was evident in $40.7 \%$ of and generic drugs were prescribed in $19.4 \%$ of all prescriptions. Name of patient, age, and sex were present in $100 \%$ and so the name, signature and medical registration number of the prescriber (Table 1).

Table 1. Percentage of Prescriptions Containing prescriber's and Patient's Information.

\begin{tabular}{|c|c|c|}
\hline & Information & Percentage \\
\hline Prescriber & Name & $100 \%$ \\
\hline & Signature & $100 \%$ \\
\hline & License number & $100 \%$ \\
\hline & Address & $0 \%$ \\
\hline Patient & Name & $100 \%$ \\
\hline & Age & $100 \%$ \\
\hline & Sex & $100 \%$ \\
\hline & Address & $0 \%$ \\
\hline & Diagnosis & $0 \%$ \\
\hline & History of allergy & $0 \%$ \\
\hline
\end{tabular}

None of the prescription contained address of patient, diagnosis of complaint or a history of allergy. The dose of the prescribed drug and the route and frequency of administration were present in $73.2 \%$ and $5.6 \%$ of prescriptions respectively whereas duration of treatment was mentioned in all prescriptions (Table 2).

Table 2. Percentage of prescriptions containing drug information.

\begin{tabular}{|c|c|}
\hline Information & Percentage \\
\hline Generic prescribing & $19.4 \%$ \\
\hline Dose & $73.2 \%$ \\
\hline Route of administration & $5.6 \%$ \\
\hline Frequency of administration & $5.6 \%$ \\
\hline Duration of treatment & $100 \%$ \\
\hline
\end{tabular}

As shown in Table 3, patients were prescribed one, two, three, four or more than four drugs per prescription in $21.3 \%, 22.18 \%, 18.56 \%, 11.94 \%$ and $25.66 \%$ respectively.

Table 3. Number of drugs per prescription.

\begin{tabular}{|c|c|}
\hline Number of drugs/prescription & Percentage prescriptions \\
\hline One drug & $21.30 \%$ \\
\hline Two drugs & $22.18 \%$ \\
\hline Three drugs & $18.56 \%$ \\
\hline Four drugs & $11.94 \%$ \\
\hline More than four drugs & $25.66 \%$ \\
\hline
\end{tabular}

The most commonly prescribed therapeutic classes of drugs are shown in Table 4.

Four therapeutic classes of drugs were most commonly used as antihypertensive agents comprising $35.68 \%$ of all prescriptions studied. These include diuretics $(28.39 \%)$, beta adrenoceptor blockers $(25.93 \%)$, angiotensin-II receptor blockers $(24.28 \%)$ and angiotensin converting enzyme (ACE) inhibitors $(6.99 \%)$. Other commonly prescribed therapeutic classes include antiepileptics (30.9\%), antidiabetics (19.49\%), nonsteroidal antiinflammatory drugs (NSAIDs $8.19 \%$ ) and anticoagulants $(5.57 \%)$. The most frequently prescribed drugs of each of the therapeutic classes are shown in Table 4. The most commonly prescribed drugs of each therapeutic class are also shown in Table 4.

Table 4. Most Commonly prescribed therapeutic classes and drug(s) of each class.

\begin{tabular}{|c|c|c|c|}
\hline Therapeutic class & $\begin{array}{c}\text { Percentag } \\
\mathrm{e}\end{array}$ & Drug (s) & $\begin{array}{c}\text { Percentag } \\
\mathrm{e}\end{array}$ \\
\hline \multirow[t]{4}{*}{ 1. Diuretics } & $28.39 \%$ & & \\
\hline & & Furosemide & $44.54 \%$ \\
\hline & & Spironolactone & $32.65 \%$ \\
\hline & & Indapamide & $21 \%$ \\
\hline \multirow[t]{4}{*}{ 2. Beta blockers } & $25.93 \%$ & & \\
\hline & & Bisoprolol & $44.67 \%$ \\
\hline & & Atenolol & $36.45 \%$ \\
\hline & & Metoprolol & $23.38 \%$ \\
\hline \multirow[t]{4}{*}{$\begin{array}{l}\text { 3. Angiotensin }-\mathrm{II} \\
\text { receptor blockers }\end{array}$} & $24.28 \%$ & & \\
\hline & & Irbesartan & $43.72 \%$ \\
\hline & & Candesartan & $37.21 \%$ \\
\hline & & Valsartan & $19.34 \%$ \\
\hline \multirow[t]{4}{*}{ 4. ACE inhibitors } & $6.99 \%$ & & \\
\hline & & Perindpril & $44.67 \%$ \\
\hline & & Ramipril & $36.62 \%$ \\
\hline & & Lisinopril & $21.25 \%$ \\
\hline \multirow[t]{4}{*}{ 5. Antiepileptic } & $30.90 \%$ & & \\
\hline & & Sodium valproate & $60.38 \%$ \\
\hline & & Carbamazepin & $16.99 \%$ \\
\hline & & Gabapentin & $15.09 \%$ \\
\hline \multirow[t]{4}{*}{ 6. Antidiabetic } & $19.49 \%$ & & \\
\hline & & Metformin & $58.71 \%$ \\
\hline & & Gliclazide & $34.33 \%$ \\
\hline & & Glimepiride & $4.98 \%$ \\
\hline \multirow[t]{3}{*}{ 7. NSAIDs } & $8.19 \%$ & & \\
\hline & & Ibuprofen & $52.4 \%$ \\
\hline & & Diclofenac sodium & $34.67 \%$ \\
\hline \multirow[t]{3}{*}{ 8. Anticoagulants } & $5.57 \%$ & & \\
\hline & & Warfarin sodium & $54.8 \%$ \\
\hline & & Dabigatrin & $35.2 \%$ \\
\hline
\end{tabular}

\section{Discussion}

The study was carried out to investigate the trends in drug prescribing by consultant physicians. A total 1239 prescriptions were collected from the outpatient pharmacy of a governmental; general hospital in Sharjah, United Arab Emirates. The prescription were analyzed for the presence of information with regard to patient, prescriber and the prescribed drugs employing drug use indicators described by WHO [2,3] and guidelines for safe prescribing [5,6,7].

Difficult to read prescriptions constituted about $60 \%$ of all screened encounters. This is similar to that reported in one study for Saudia Arabia [8] but much higher than that reported by another study for the same country [9] or that for USA [10] or for Sudan [11]. However, in the first Saudi study illegible encounters included those containing a single unclear word or dose unit [8] whereas in our study, 
the difficult to read prescriptions were those with unreadable drug names. The large number of unclear prescriptions is a main source of dispensing errors especially with lookalike drugs and can result in harmful effects [12]. The average number of drugs per encounter was 2.2. This is strikingly similar of that described for the study in Dubai [1] which is slightly more than the optimal WHO figure of 2 drugs per prescription but similar to figures observed in China [13] and higher than 1.4 and 1.6 for Bangladesh [14] and Lebanon [15] respectively. In our study, only $11.94 \%$ of prescriptions contained four drugs while $25.66 \%$ contained more than four drugs per encounter. Our results for prescriptions with more than four drugs are only slightly less than that recently reported for India [16]. Polypharmacy is a common defect in prescription writing which contributes to the risk of increased incidence of adverse drug reactions and harmful drug interactions. However, a majority of prescription $(87 \%)$ were for chronic disease states like hypertension, diabetes and epilepsy. These clinical conditions may require multiple drug therapy and hence polypharmacy may be acceptable [17]. Prescribing generic drugs though higher than that of $4 \%$ in the earlier Dubai study [1] but it is still much lower than that reported for Bangladesh [14], China [13], India [16] and Iran [18] where generic prescribing reached $78 \%, 73.4 \%, 27.3 \%$ and $96 \%$, respectively. The low $\%$ generic prescribing in our study can be attributed to the lack of emphasis on that aspect in medical training and practice and also to the influence of promotional activities of drug industry in the country. Generic prescribing tends to reduce cost and rationalize drug use [3]. Introduction of concepts of list of essential drugs, generic prescribing and good prescription writing in medical curriculum seems to be a must. In the present study none of the prescriptions analyzed indicated either diagnosis of the complaint targeted by the prescribed drug or a history of allergy. This is in contrast to prescribing in Saudi Arabia where diagnosis was missing in only $15.1 \%$ of prescriptions [8]. In this context, it is worth noting that the name of the prescribed drug does not always reflect its therapeutic indication particularly for drugs with multi therapeutic uses. Moreover, ignorance of history of allergy, if any, may prove hazardous to the patient. Although the dose of the drug was mentioned in majority (73.2\%) of prescriptions, it was deficient in slightly more than $25 \%$ of prescriptions. In addition, both route and frequency of administration was lacking in about $95 \%$ of prescriptions. This may add to the role of the dispensing pharmacist as complimentary to that of the prescribing physician. A competent pharmacist plays his role to the full as an active member of the health care team for the benefit of the patient. This is more easier for a hospital pharmacist who can communicate with the prescribing physician in the same health facility as compared to a community pharmacist. However, with the drugs prescribed in this study, it is important for the prescriber to be in charge of dose, route and frequency of administration. This is particularly important in case of antiepileptic and antihypertensive drugs where doses are selected on basis of plasma drug levels and other parameters that require frequent monitoring by the physician.

Results of the present study clearly indicate that more than $85 \%$ of the prescriptions were issued for hypertensive, epileptic and diabetic patients. This is expected in such a general hospital.
No attempts were made to determine the quality of diagnosis, or adequacy of drug treatment. Both these essential measures are among the limitations of drug use studies utilizing the WHO core drug use indicators [2].

\section{Conclusion}

The present study pinpointed areas for further improvement to prescription writing and suggests that feedback through personal interviews and workshops may be an effective intervention to enforce rational drug use.

Since assessment of drug use is important for clinical, educational and economic purposes [19], it seems reasonable to promote rational drug prescribing through stressing the importance of periodical prescription analysis studies and the need to include concepts of essential drug list [20] and prescription writing in medical curriculum and continuing medical education programs.

\section{Acknowledgments}

We are greatly indebted to Dr. Adeeba Hassan for providing the prescriptions and answering our frequent queries.

\section{Competing Interest}

The authors declare that there is no conflict of interest.

\section{References}

[1] Sharif S.I, Al-Shaqra, M., Hajjar H, Shamout A. and Wess L, Patterns of drug prescribing in a hospital in Dubai, United Arab Emirates. Libyan J. Med. 3 (1): 10-12. March, 2008.

[2] International Network for Rational Use of drugs and World Health Organization. How to investigate drug use in health facilities: selected drug use indicators. EDM Research Series No. 7 [WHO/DAP/93.1]. Geneva: World Health Organization. 1993.(Accessed October 10, 2012).

[3] Quick JD, Hogerzeil HV, Velasquez G, and Rago L, Twenty-five years of essential medicines. Bull WHO. 80(11):913-14. 2002.

[4] The Pharmaceutical Professions and Institutions.UAE Federal Law No: 4, 1983.(Accessed, October, 12,2012).

[5] DeVries TP et al., eds. Guide to good prescribing: a practical manual. Geneva, World Health Organization;515(WHO/DAP/94.11). 1995 (Accessed October, 15, 2012).

[6] Prescription writing. In: British national formulary, No. 41. London, British Medical Association \& Royal Pharmaceutical Society of Great Britain, 4-5. 2000.

[7] Safe Writing. In: Lacy CF et al., eds. Drug information handbook, $9^{\text {th }}$ ed. Cleveland,Ohio,Lexi-comp,2001; 12.

[8] Irshaid,YM;Al Homrany,M; Hamdi, AA; Adjepon-Yamoah, KK and Mahfouz,AA. Compliance with good practice in prescription writing at outpatient clinic in Saudi Arabia. East Mediterr Health J. 11(5, 6):922-28. 2005.

[9] Balbaid OM, and Al-Dawood KM. Assessment of physician's prescribing practices at Ministry of Health hospitals in Jeddah city,Saudi Arabia. Saudi Medical Journal, 19: 28-35. 1988.

[10] Meyer TA. Improving the quality of the order-writing process for inpatient orders and outpatient prescriptions. American Journal of Health-System Pharmacy, 57 (Suppl. 4): S18-2. Dec., 2000.

[11] Yousif E, Ahmed AM, Abdalla ME, and Abdelgadir MA. Deficiencies in medical prescriptions in a Sudanese hospital. East Mediterr Health J. 12(6):915-18.Nov. 2006.

[12] Charatan F. Family compensated for death after illegible prescription. British Medical journal, 319: 1456.1, Dec., 1999. 
[13] Jun Z, Linyun L, Che Z, Yuanrong Y, Fengxi G and Heng Z. Analysis of outpatient prescription indicators and trends in Chinese Jingzhou Area between September 1and 10, 2006-2009. frican Journal of Pharmacy and Pharmacology. 5(2):270-275. Feb. 2011.

[14] Guyon AB, Barman A, Ahmed JU, Ahmed AU, and Alam MS. A baseline survey on use of drugs at the primary health care level in Bangladesh. Bull WHO 72(2):265-71.Aug. 1994.

[15] Hamadeh GN, Dickerson LM, Saab BR, and Major SC. Common prescriptions in ambulatory care in Lebanon. Ann Pharmacother. 35:636-40. May, 2001.

[16] Vijayakumar TM, Sathyavati D, Subhashini T, Sonika G, and Dhanaraju MD. Assessment of prescribing trends and rationality of drug prescribing. International Journal of Pharmacology, 7 (1):140-43. 2011.
[17] Chobanian AV, Bakris GL, Black HR, Cushamn WC, Green LA and Izzo JL. The seventh report of the joint national committee on prevention, detection, evaluation and treatment of high blood pressure. The JNC 7 report. J. Am. Med. Assoc. 289:2560-75.May, 2003.

[18] Ghadimi H, Esmaily HM, and Wahlstrom R. General practitioners' prescribing patterns for the elderly in a province of Iran. Pharmacoepidemiol Drug Saf. 20(5):482-487. May 2011.

[19] Nazima Y, Mirza N, Desi S, and Ganguly B. Prescribing pattern in pediatric out-patient department in Gujarat., Bangladesh Journal of Pharmacol., 4:39-42. Sep. 2009.

[20] WHO., 2010. Model list of essential medicines $16^{\text {th }}$ list. http;//www.who.int/medicines/publications/essentialmedicines/en/. \{Accessed October 9, 2012). 